\title{
ANALISIS PENGARUH PENGALAMAN KEUANGAN DAN TINGKAT PENDAPATAN TERHADAP PERILAKU KEUANGAN KELUARGA DI KECAMATAN PURWOKERTO TIMUR
}

\author{
Wida Purwidianti ${ }^{1}$ dan Rina Mudjiyanti ${ }^{2}$ \\ Fakultas Ekonomi dan Bisnis Universitas Muhammadiyah Purwokerto \\ Jalan Raya Dukuhwaluh Purwokerto 53182 \\ Telp 0281-636751 ext 223 \\ ${ }^{1}$ wieda_76@Yahoo.Com \\ 2rina.mudjiyantie@Yahoo.com
}

\begin{abstract}
This study entitled "Effect Analysis of Financial Experience and Income Level Toward Family Financial Behavior In District East Purwokerto. This study took a sample of 85 heads of families living in six villages in the district of East Purwokerto. The results showed financial experience have a significant positive effect on the behavior of the family finances. While the variable income levels have no significant impact on the financial behavior of families in East Purwokerto.
\end{abstract}

Keywords: Financial Experience, Income Level and Family Financial Behavior

\begin{abstract}
Abstrak: Penelitian ini berjudul Pengaruh Analisis Pengalaman Keuangan dan Tingkat Pendapatan terhadap Perilaku Keuangan Rumah tangga di Kabupaten Purwokerto Timur. Penelitian ini mengambil sampel 85 kepala keluarga yang tinggal di enam desa di Kabupaten Purwokerto Timur. Hasil penelitian menunjukkan pengalaman keuangan memberikan efek positif dan signifikan terhadap perilaku keuangan keluarga. Sedangkan variabel tingkat pendapatan tidak memiliki dampak yang signifikan terhadap perilaku keuangan keluarga di Purwokerto Timur.
\end{abstract}

Kata kunci: Pengalaman Keuangan, Tingkat Pendapatan dan Keluarga Perilaku Keuangan

\section{PENDAHULUAN}

Individu, perusahaan dan masyarakat secara keseluruhan tidak bisa mendapat semua yang mereka inginkan, mereka harus membuat pilihan. Pada setiap kegiatannya mereka harus menentukan pilihan yang terbaik. Dalam kegiatan memproduksi atau mengkonsumsi barang dan jasa, setiap pelaku kegiatan ekonomi harus membuat pilihan-pilihan. Tujauannya adalah agar sumberdaya yang tersedia dapat digunakan secara efisien dan dapat mewujudkan kesejahteraan yang paling maksimum kepada individu dan masyarakat.

Financial management behavior berhubungan dengan tanggung jawab keuangan seseorang mengenai cara pengelolaan keuangan mereka, Ida dan Cinthia (2010). Tanggungjawab keuangan adalah proses pengelolaan keuangan dan aset lainnya dengan cara yang dianggap produktif. Hal ini juga berkaitan dengan proses menguasai penggunaan aset keuangan. Ada beberapa elemen yang masuk dalam pengelolaan uang yang efektif, seperti pengaturan anggaran, menilai perlunya pembelian dan utang pensiun dalam kerangka waktu yang wajar.

Dalam Yulianti dan Silvy (2013) Hilgret \& Jeanne menyatakan bahwa keputusan keuangan yang baik dan benar dibutuhkan untuk meningkatkan pendapatan, mengelola pengeluaran, pembayaran pajak agar manajemen keuangan keluarga menjadi baik. Pengalaman masa kecil yang positif tentang mengelola keuangan, lingkungan sosial, dan sikap terhadap penghematan memainkan peran manajemen keuangan dalam perilaku keluarga di masa yang akan datang. Hasil penelitian Yulianti dan Silvy (2013) menunjukkan bahwa pengetahuan keuangan dan pengalaman keuangan berpengaruh terhadap perilaku perencanaan investasi keuangan keluarga.

Tingkat pendapatan adalah total pendapatan kotor individu yang berasal 
dari upah, gaji, usaha dan pengembalian dari investasi. Besar kemungkinan bahwa individu dengan pendapatan yang lebih akan menunjukkan perilaku keuangan lebih bertanggung jawab, terkait dana yang tersedia memberikan kesempatan untuk bertindak lebih bertanggung jawab. Dalam Andrew dan Linawati (2014) hasil penelitian Hilgert, et al responden menyatakan dengan pendapatan lebih rendah cenderung membayar tagihan kurang tepat waktu dibandingkan dengan pendapatan yang lebih tinggi.

Penelitian ini bertujuan untuk menguji pengaruh pengalaman keuangan dan tingkat pendapatan terhadap perilaku keuangan keluarga di Kecamatan Purwokerto Timur. Penilitian ini perlu dilakukan kerena perilaku keuangan merupakan isu yang banyak dibicarakan di Indonesia saat ini. Hal tersebut disebabkan banyak masyarkat Indonesia yang mempunyai kecenderungan melakukan perilaku konsumsi jangka pendek tanpa mempertimbangkan kebutuhan untuk jangka panjang.

Masalah penelitian ini secara spesifik dapat dijelaskan sebagai berikut:

1. Apakah pengalaman keuangan mempunyai pengaruh yang positif terhadap perilaku keuangan keluarga?

2. Apakah tingkat pendapatan mempunyai pengaruh yang positif terhadap perilaku keuangan keluarga?

\section{TINJAUAN PUSTAKA}

\section{Perilaku Keuangan}

Dalam Kholilah dan Iramani, 2013 dinyataka bahwa financial management behavior adalah kemampuan seseorang dalam mengatur (perencanaan, penganggaran, pemerikasaan, pengelolaan, pengendalian, pencarian dan penyimpanan) dana keuangan sehari-hari. Dalam praktiknya, manajemen perilaku keuangan ini terbagai menjadi tiga hal utama yaitu konsumsi, tabungan dan investasi.

Financial management behavior berhubungan dengan tanggung jawab keuangan seseorang mengenai cara pengelolaan keuangan mereka, Ida dan Cinthia (2010). Tanggungjawab keuangan adalah proses pengelolaan keuangan dan aset lainnya dengan cara yang dianggap produktif. Hal ini juga berkaitan dengan proses menguasai penggunaan aset keuangan. Ada beberapa elemen yang masuk dalam pengelolaan uang yang efektif, seperti pengaturan anggaran, menilai perlunya pembelian dan utang pensiun dalam kerangka waktu yang wajar.

\section{Pengalaman Keuangan}

Dalam Yulianti dan Silvy (2013) Hilgret \& Jeanne menyatakan bahwa keputusan keuangan yang baik dan benar dibutuhkan untuk meningkatkan pendapatan, mengelola pengeluaran, pembayaran pajak agar manajemen keuangan keluarga menjadi baik. Pengalaman masa kecil yang positif tentang mengelola keuangan, lingkungan sosial, dan sikap terhadap penghematan memainkan peran manajemen keuangan dalam perilaku keluarga di masa yang akan datang. Motivasi individu untuk hidup lebih baik dengan belajar dari pengalaman. Pengalaman dapat dipelajari dari pengalaman pribadi, teman, keluarga atau orang lain yang lebih berpengalaman sehingga memperbaiki dalam pengelolaan, pengambilan keputusan maupun perencanaan investasi keluarga.

\section{Tingkat Pendapatan}

Dalam Andrew dan Linawati (2014) Hilgert et al menyatakan bahwa personal income adalah total pendapatan kotor tahunan seorang individu yang berasal dari upah, perusahaan bisnis dan berbagai investasi. Personal income adalah penghasilan pribadi sebelum pajak. Personal income diukur berdasarkan pendapatan dari semua sumber. Komponen terbesar dari total pendapatan adalah upah dan gaji. Selain itu, ada banyak kategori lain pendapatan, termasuk pendapatan sewa, pembayaran subsidi pemerintah, pendapatan bunga dan pendapatan dividen. Personal income adalah indikator yang baik untuk permintaan konsumen masa depan meskipun tidak sempurna.

\section{Hasil Penelitian Terdahulu}

Hasil penelitian dari Yulianti dan Silvy (2013) menemukan bukti bahwa pengetahuan keuangan dan pengalaman keuangan berpengaruh terhadap perencanaan investasi keluarga. Sikap pengelola keuangan 
memoderasi dan memperkuat pengaruh pengetahuan keuangan dan tidak memoderasi pengaruh pengalaman keuangan terhadap perilaku perencanaan investasi keuangan keluarga.Hasil penelitian dari Ida dan Dwinta (2010) menyimpulkan bahwa pengetahuan keuangan berpengaruh terhadap financial management behavior tetapi locus of control dan tingkat pendapatan tidak mempunyai pengaruh terhadap financial management behavior.

Hasil penelitian Andrew dan Linawati (2014) menemukan bukti bahwa faktor demografi yang terdiri dari jenis kelamin, tingkat pendapatan dan pengetahuan keuangan mempunyai hubungan yang signifikan terhadap perilaku keuangan. Sedangkan tingkat pendidikan tidak mempunyai pengaruh yang signifikan.Mahdzan dan Tabiani Dalam Andrew dan Linawati (2014) menyatakan bahwa semakin tinggi besarnya pendapatan seseorang maka orang tersebut akan berusaha memperoleh pemahaman bagaimana cara memanfaatkan keuangan dengan cara yang lebih baik melalui pengetahuan keuangan.

Hasil penelitian Kholilah dan Irmani (2013) menemukan bukti bahwa tiadak ada pengaruh langsung pengetahuan keuangan dan pendapatan terhadap perilaku manajemen keuangan. Locus of control berpengaruh positif terhadap perilaku manajemen keuangan. Dan locus of control memediasi pengaruh pengetahuan keuangan terhadap perilaku manajemen keuangan.

\section{HIPOTESIS}

Dari landasan teori diatas dapat ditarik hipotesis dalam penelitian ini adalah sebagai berikut :

H1: Pengalaman Keuangan mempunyai pengaruh positif signifikan terhadap perilaku keuangan keluarga

H2: Tingkat Pendapatan mempunyai pengaruh yang positif signifikan terhadap perilaku keuangan keluarga

\section{METODE PENELITIAN}

Penelitian ini dilaksanakan dengan mengambil lokasi salah satu kecamatan di Kota Purwokerto yaitu Kecamatan
Purwokerto Timur. Populasi dalam penelitian ini adalaah seluruh kepala keluarga di Kecamatan Purwokerto Timur. Berdasarkan data dari Statistik Daerah Kecamatan Purwokerto Timur Jumlah kepala keluarga sebanyak 14.691 orang. Pengambilan sampel akan dilakukan dengan menggunakan metode convinience sampling. Rumus yang digunakan dalam menentukan banyaknya sampel dengan menggunakan rumus Slovin yaitu;

$\mathrm{n}=\mathrm{N} /\left(\mathrm{Nd}^{2}\right)+1$

$\mathrm{n}=14.691 /\left(14.691 .0,1^{2}\right)+1=100$

Keterangan:

$\mathrm{n}=$ jumlah sampel

$\mathrm{N}=$ jumlah populasi

$\mathrm{D}=$ tingkat presisi $\pm 10 \%$ dengan tingkat kepercayaan $90 \%$

Perilaku keuangan adalah kemampuan individu dalam mengatur keuangan yang lebih bertanggung jawab. Indikator untuk mengukur variabel ini adalah pembayaran tagihan tepat waktu, penyusunan rancangan keuangan untuk masa depan, penyisihan uang untuk tabungan, pembagian uang untuk keperluan pribadi dan keluarga (Kholilah dan Iramani, 2013). Skala yang digunakan untuk mengukur perilaku keuangan adalah skala likert dengan tidak pernah (skor 1) dan selalu (skor 5).

Pengalaman keuangan adalah kemampuan untuk membuat pertimbangan atau pengambilan keputusan investasi guna menentukan perencanaan dan pengelolaan investasi agar mengetahui kegunaan manajemen keuangan saat ini dan di masa mendatang (Sina dalam Yulianti dan Silvi, 2013). Indikator yang digunakan untuk variabel ini adalah pengalaman responden dalam berinvestasi pada perbankan, pasar modal, produk pegadaian, produk asuransi, produk dana pensiun dan produk lembaga keuangan lainnya. Skala yang digunakan untuk mengukur pengalaman keuangan adalah skala likert dengan tidak pernah (skor 1) dan selalu (skor 5).

Tingkat pendapatan adalah total pendapatan kotor individu yang berasal dari upah, gaji, usaha dan pengembalian dari investasi. Pengukuran variabel yang digunakan dalam penelitian ini adalah 
menggunakan skala interval dengan range pendapatan minimal $\mathrm{Rp} 1.000 .000$ sampai di atas $\operatorname{Rp} 5.000,000$.

Untuk mengetahui besarnya pengaruh variabel independen terhadap variabel dependen digunakan persamaan regresi linear berganda dengan persamaan sebagai berikut

$\mathrm{Y}=\mathrm{b}_{0}+\mathrm{b}_{1} \mathrm{X}_{1}+\mathrm{b}_{2} \mathrm{X}_{2}+\mathrm{e}$

Dimana :

Y : Perilaku keuangan

$\mathrm{X}_{1} \quad$ : Pengalaman Keuangan

$\mathrm{X}_{2}$ : Tingkat Pendapatan

$\mathrm{b}_{0}$ : Konstanta

$\mathrm{b}_{1 ;} \mathrm{b}_{2}$ : Koefisien regresi

Untuk mengetahui apakah regresi yang digunakan memberikan hasil yang Best Linier Unbiased Estimator (BLUE) maka dilakukan uji asumsi klasik yang meliputi uji normalitas, uji multikolinieritas, uji autokorelasi dan uji heteroskedasrisitas.Pengujian hipotesis dilakukan dengan menggunakan model regresi berganda. Pada penelitian ini digunakan $\alpha$ sebesar 0,05 yang berarti tingkat keyakinannya sebesar $95 \%$. Berdasarkan batasan tersebut, maka untuk menguji signifikansi secara parsial model regresi berganda digunakan kriteria apabila nilai koefisin regresi bernilai positif dan nilai probabiliti (p)-t lebih kecil dari 0,05 dinyatakan signifikan pada taraf kesalahan $5 \%$. Dengan demikian berarti variabel independen berpengaruh terhadap variabel dependen, dimana besarnya pengaruh dapat dilihat dari nilai koefisien regresi masingmasing variabel independen.

\section{HASIL DAN PEMBAHASAN}

\section{Statistik Deskriptif}

Dalam penelitian ini, pengambilan sampel akan dilakukan dengan menggunakan metode convinience sampling. Sampel adalah sebagian atau wakil populasi yang diteliti. Berdasarkan rumus Slovin sampel yang harus diteliti berjumlah 100 orang.

Tabel 5.1 Data Penelitian

\begin{tabular}{lc}
\hline \multicolumn{1}{c}{ Keterangan } & Jumlah data \\
\hline Jumlah kuisioner yang & 100 \\
dibagikan & 15 \\
Jumlah kuisioner yang data nya & 85 \\
lengkap & \\
Jumlah data yang dapat & \\
dianalisis & \\
\hline
\end{tabular}

Statistik deskriptif memberikan gambaran atau deskripsi suatu data yang dilihat dari nilai minimum, nilai maksimum, nilai ratarata (mean) dan deviasi standar dari setiap variabel yang digunakan. Tabel 5.2 dibawah ini menunjukkan hasil uji statistik deskriptif setiap variabel penelitian.

Tabel 5.2 Stastistik Deskriptif

\begin{tabular}{lccccc}
\hline & N & Minimum & Maximum & Mean & $\begin{array}{c}\text { Std. } \\
\text { Deviation }\end{array}$ \\
\hline Perilaku & 85 & 2.25 & 5.00 & 4.1000 & .77364 \\
Pengalaman & 85 & 1.00 & 4.17 & 1.3941 & .49591 \\
Pendapatan & 85 & 1.00 & 4.00 & 2.1294 & .98547 \\
Valid N (listwise) & 85 & & & & \\
\hline
\end{tabular}

Berdasarkan tabel diatas dapat dilihat bahwa rata-rata tabulasi data jawaban responden untuk variabel $\mathrm{Y}$ (Perilaku Keuangan) sebesar 4,1 ini berarti rata-rata responden sering melakukan pembayaran tagihan tepat waktu, melakukan penyusunan rancangan keuangan masa depan, menyisihkan uang tabungan dan membagi uang untuk keperluan pribadi dan keluarga . Rata-rata nilai variabel pengalaman keuangan sebesar 1,3941 berarti rata-rata responden jarang mempunyai pengalaman berinvestasi dalam bidang keuangan. Rata-rata variabel tingkat pendapatan mempunyai skor 2,1294 artinya rata-rata tingkat pendapatan responden berada pada range Rp 1.000.000-Rp. 3.000.0000.

\section{Uji Validitas Dan Realibilitas}

Berdasarkan perhitungan program SPSS semua item pertanyaan untuk variabel Perilaku Keuangan, Pengalaman Keuangan, 
dan Tingkat Pendapatan sudah valid karena nilai pearson correlation lebih besar dari nilai $\mathrm{r}$ tabel. Nilai Cronbach alpha untuk variabel Perilaku Keuangan sebesar 0,752 dan Pengalaman Keuangan sebesar 0,681 Karena nilai Cronchbach alpa untuk semua variabel lebih besar dari $r$ tabel maka kuisioner dapat dikatakan reliabel. Sedangkan tingkat pendapatan tidak di uji realibilitasnya karena menggunakan skala interval.

\section{Hasil Regresi}

Hasil regresi yang menunjukkan pengaruh variabel independen terhadap variabel dependen dapat dilihat pada tabel 5.3 di bawah ini:

Tabel 5.3. Hasil Uji Regresi

\begin{tabular}{clccccc}
\hline \multirow{2}{*}{ Model } & \multicolumn{2}{c}{ Unstandardized Coefficients } & $\begin{array}{c}\text { Standardized } \\
\text { Coefficients }\end{array}$ & \multirow{2}{*}{ T } & Sig. \\
\cline { 3 - 5 } & & $\mathbf{B}$ & Std. Error & Beta & & \\
\hline \multirow{2}{*}{1} & (Constant) & 13.134 & 1.155 & & 11.371 & .000 \\
& Pengalaman & .429 & .104 & .412 & 4.104 & .000 \\
& Pendapatan & -.150 & .315 & -.048 & -.476 & .635 \\
\hline
\end{tabular}

Tabel di atas menunujukkan hasil uji regresi pengaruh variabel Pengalaman Keuangan dan Tingkat Pendapatan terhadap Perilaku Keuangan Keluarga. Hasil tersebut memperlihatkan bahwa variabel pengalaman keuangan berpengaruh positif dan signifikan terhadap perilaku keuangan. Hal ini ditunjukkan dengan nilai signifikansi dibawah angka 0,05 .

\section{Hasil Uji Asumsi Klasik}

\section{Uji Normalitas}

Hasil uji normalitas tersebut di atas menunjukkan nilai Kolmogorow-Smirnov sebesar 1,058 signifikan pada tingkat 0,213.
Hasil uji tersebut mempunyai nilai $\mathrm{p}>0,05$ yang berarti error terdistribusi secara normal

\section{Uji Heteroskedastisitas}

Pengujian dapat dilakukan dengan dengan uji Glejser dengan cara meregresikan nilai absolut residual dengan variabel independen. Apabila nilai $\mathrm{p}$ dari koefisien regresi $<0,05$ maka terjadi heteroskedastisitas. Tabel 5.4 menunjukkan hasil uji heteroskedastisitas

Tabel 5.4 menunjukkan nilai $\mathrm{p}$ dari koefisien regresi $>0,05$ untuk semua variabel independen hal ini berarti model bebas dari heteroskedastisitas

Tabel 5.4 : Hasil Uji Heteroskedastisitas

Coefficients $^{\text {a }}$

\begin{tabular}{|c|c|c|c|c|c|c|}
\hline & \multirow{2}{*}{ Model } & \multicolumn{2}{|c|}{$\begin{array}{c}\text { Unstandardized } \\
\text { Coefficients }\end{array}$} & \multirow{2}{*}{$\begin{array}{c}\begin{array}{c}\text { Standardized } \\
\text { Coefficients }\end{array} \\
\text { Beta }\end{array}$} & \multirow[t]{2}{*}{$\mathbf{t}$} & \multirow{2}{*}{ Sig. } \\
\hline & & B & Std. Error & & & \\
\hline \multirow{3}{*}{1} & (Constant) & 2.952 & .586 & & 5.041 & .000 \\
\hline & Pengalaman & -.099 & .053 & -.201 & -1.869 & .065 \\
\hline & Pendapatan & .125 & .160 & .084 & .780 & .438 \\
\hline a. De & ident Variable & & & & & \\
\hline
\end{tabular}




\section{Uji Multikolinearitas}

Tabel 5.5 dibawah ini menunjukkan hasil uji multikoliniertias untuk persamaan Tabel 5.5 Hasil Uji Multikolinieritas

\begin{tabular}{|l|c|c|c|}
\hline \multicolumn{2}{c}{ Model } & \multicolumn{2}{c}{ Collinearity Statistics } \\
\cline { 3 - 4 } \multicolumn{2}{c}{} & \multicolumn{2}{c}{ Tolerance } \\
\hline \multirow{3}{*}{1} & VIF \\
\cline { 2 - 4 } & Pengalaman & 1.000 & 1.000 \\
\cline { 2 - 4 } & Pendapatan & 1.000 & 1.000 \\
\hline
\end{tabular}

Hasil uji ini menunjukkan nilai VIF mendekati 1 untuk semua variabel independen ini berarti tidak ada multikolinearitas antar variabel. Hal ini juga diperkuat dengan nilai tolerance variabel independen $>0,10$ yang berarti tidak ada korelasi antar variabel independen yang nilainya lebih dari 95\%.

\section{PEMBAHASAN PENGUJIAN HIPOTESIS}

Tabel 6 di bawah ini merupakan ringkasan hasil pengujian hipotesis sebagai berikut:

Tabel 5. 6: Ringkasan Pengujian Hipotesis

\begin{tabular}{ccccccc|}
\hline Variabel & Koefisien & t hitung & Signifikan & Kesimpulan \\
\hline Pengalaman Keuangan & .429 & 4.104 & .000 & Diterima \\
Tingkat Pendapatan & -.150 & -.476 & .635 & Ditolak \\
\hline
\end{tabular}

Berdasarkan tabel diatas dapat diketahui bahwa pengalaman keuangan (X1), berpengaruh positif signifikan terhadap perilaku keuangan keluarga di Kecamatan Purwokerto Timur. Sedangkan tingkat pendapatan (X2) tidak mempunyai pengaruh yang signifikan terhadap perilaku keuangan keluarga.

\section{Pengalaman Keuangan dan Perilaku Keuangan}

Hasil pengujian tentang pengaruh pengalaman keuangan terhadap perilaku keuangan menunjukkan hasil bahwa pengalaman keuangan mempunyai pengaruh yang positif dan signifikan terhadap perilaku keuangan. Hasil penelitian ini mendukung penelitian dari Yulianti dan Silvy (2013) yang menemukan bukti bahwa pengalaman keuangan mempunyai pengaruh terhadap perilaku perencanaan investasi keuangan di Surabaya. Menurut Hilgert dan Jeanne dalam Yulianti dan Silvy (2013), keputusan keuangan yang baik dan benar dibutuhkan untuk meningkatkan pendapatan, mengelola pengeluaran, pembayaran pajak, agar manajemen keuangan keluarga menjadai baik. Pengalaman masa kecil yang positif tentang mengelola keuangan, lingkungan social dan sikap terhadap penghematan memainkan peran manajemen keuangan dalam perilaku keluarga di masa yang akan datang.

\section{Tingkat Pendapatan Dan Perilaku Keuangan}

Hipotesis kedua yang menyatakan bahwa tingkat pendapat berpengaruh positif signifikan terhadap perilaku keuangan tidak terbukti. Hal ini mandukung penelitian yang dilakukan oleh Ida dan Dwinta (2010) dan Al kholilah dan Iramani (2013) yang menemukan bukti bahwa personal income tidak berpengaruh terhadap financial management behavior. Hasil penelitian ini tidak mendukung penelitian Andrew dan Linawati (2014) yang menemukan bukti bahwa tingkat pendapatan mempunyai hubungan yang signifikan tehadap perilaku keuangan karyawan swasta di Surabaya.

Hasil penelitian ini menunjukkan bahwa tingkat pendapatan tidak berpengaruh terhadap perilaku keuangan, hal ini ini dimungkinkan karena responden dalam penelitian ini adalah 
masyarakat (bapak atau ibu) dari kelompok masyarakat dengan tingkat pendapatan yang berbeda dan jumlah tanggungan yang berbeda pula. Sehingga setiap kepala keluarga dalam mengalokasikan keuangan yang dimilikinya akan berbeda-beda pula. Koefisien regresi untuk variabel tingkat pendapatan sebesar $-0,150$ menunjukkan bahwa pada saat tingkat pendapatanya meningkat maka perilaku keuangannnya menurun, hal ini dimungkin responden yang memiliki pendapatan rendah lebih mudah dalam mengalokasikan keuangan yang dimilikinya.

\section{KESIMPULAN DAN SARAN}

\section{Kesimpulan}

Hasil pengujian hipotesis pada penelitian ini dapat disimpulkan sebagai berikut:

1. Hipotesis pertama yang menyatakan bahwa pengalaman keuangan berpengaruh positif signifikan terhadap perilaku keuangan keluarga diterima

2. Hipotesis kedua yang menyatakan tingkat pendapatan berpengaruh positif signifikan terhadap perilaku keuangan keluarga ditolak

\section{Saran}

Saran yang dapat pertimbangkan untuk penelitian selanjutnya yaitu:

1. Penelitian selanjutnya perlu menambahkan lain yang mempengaruhi perilaku keuangan keluarga misalnya tingkat pendidikan

2. Objek penelitian dapat lebih difokuskan kepada kalangan keluarga tertentu.

\section{DAFTAR PUSTAKA}

Andrew, Vincentius dan Linawati, Nanik. 2014. Hubungan Faktor Demografi dan Pengetahuan Keuangan Dengan Perilaku Keuangan Karyawan di Surabaya. Finesta Vol 2 No 2

Barlian, dkk. 2012. Pengelolaan Keuangan oleh Pengusaha Perempuan pada Beberapa Bisnis Kreatif di Bandung. Penelitian Kelompok. Univ Katolik Parahyangan. Bandung.
Ghozali, Imam. 2006. Aplikasi Analisis Multivariate Dengan Program SPSS. Badan Penerbit Universitas Diponogoro. Semarang.

Gujarati, Damodar N. 2003. Basic Econometrics Fourth Edition. Mc Graw Hill. New York.

Ida dan Dwinta CY. 2010. Pengaruh Locus Of Control, Financial Knowledge, Income Terhadap Financial Management Behavior. Jurnal Bisnis dan Akuntansi. Vol 12, No. 3, Desember, Univ Kristen Maranatha

Kholilah, Naila Al dan Iramani, Rr. 2013. Studi Financial Management Behavior Pada Masyarakat Surabaya. Journal of Business and Banking Vol. 3 No 1, Mei

Masdar. Zaiful. 2011. Perencanaan Keuangan Komunitas Miskin di Perkampungan Vatutela. Jurnal Academica. Fisip Untad. Vol 3 No 01 Februari

Panca Nugraha, Khanifan Setya. 2015. Pengaruh Monitoring Control Dan Kondisi Adverse Selection Terhadap Eskalasi Komitmen Pengambilan Keputusan Investasi Dengan Gender Dan Locus Of Control Sebagai Variabel Pemoderasi (Studi Kasus Pada Mahasiswa Fakultas Ekonomi Universitas Negeri Yogyakarta). Skripsi. Fakultas Ekonomi UNY

Rusli, Syahrul. 2014. Literasi Keuangan. Diunduh dari WWW. Google. Com

Sriyati dan Steelyana, Evi. 2013. Analisis Pengaruh Karakteristik Usia, Rencana Investasi Dan Pengetahuan Investasi Terhadap Perilaku Investasi Pada Wanita Bekerja (Studi Kasus Di Jakarta Tahun 2013).

Subiaktono. 2013. Pengaruh Personality Traits Terhadap Perencanaan Keuangan Keluarga. Jurnal Dinamika Manajemen. Vol 4, No 2, Univ Semarang

Suhartini D, Renanta JA. 2007. Pengelolaan 
Keuangan Keluarga Pedagang Etnis Cina. Jurnal Riser Ekonomi dan Bisnis. Vol 7, No 2. September. UPN. Yogyakarta

Shalahuddinta A, Susanti. 2014. Pengaruh Pendidikan Keuangan di Keluarga, Pengalaman Bekerja dan Pembelajaran di Perguruan Tinggi Terhadap Literasi Keuangan. Universitas Negeri Surabaya Yulianti, Norma dan Silvy Meliza. 2013. Sikap Pengelola Keuangan Dan Perilaku Perencanaan Investasi Keluarga Di Surabaya. Journal of Business and Banking Vol. 3 No 1, Mei 